\title{
Highly purified chondroitin sulfate: a literature review on clinical efficacy and pharmacoeconomic aspects in osteoarthritis treatment
}

\author{
Jean-Yves Reginster ${ }^{1,2,3}$ (D) Nicola Veronese ${ }^{4}$
}

Received: 18 May 2020 / Accepted: 22 June 2020 / Published online: 7 July 2020

(c) The Author(s) 2020

\begin{abstract}
Osteoarthritis (OA) is the most prevalent musculoskeletal disease and a major cause of negative relevant outcomes, associated with an ever-increasing societal burden. Pharmaceutical-grade chondroitin sulfate (CS) was repeatedly reported to reduce pain and improve function in patients with OA. This article aims to review the evidence for the role of highly purified (hp) CS (Condrosulf ${ }^{\circledR}$, IBSA) in the treatment of OA. We collected and reported evidence concerning (1) efficacy of hpCS $800 \mathrm{mg} / \mathrm{day}$ in the treatment of OA affecting the knee, hand and hip; (2) efficacy and safety of hpCS $1200 \mathrm{mg} /$ day also in the oral gel formulation; (3) the safety profile of hpCS; (4) the difference of hpCS and pharmaceutical-grade formulations versus food supplements; (5) pharmacoeconomic added value of hpCS. The data support that hpCS is an effective and safe treatment of OA, with its effect already evident at 30 days; in addition, its beneficial action is prolonged, being maintained for at least 3 months after the drug is discontinued. Full safety reports' analyses confirm that CS is safe to use and has almost no side effects, in particular, it showed better gastrointestinal tolerance if compared with non-steroidal anti-inflammatory drugs (NSAIDs). Moreover, the therapeutic strategy has proved to be cost-effective: treatment with CS reduced the use of NSAIDs and their side effects.
\end{abstract}

Keywords Chondroitin sulfate · Osteoarthritis · Knee osteoarthritis · Hip osteoarthritis · Hand osteoarthritis · Economic analysis

\section{Introduction}

Osteoarthritis (OA) is a chronic inflammatory degenerative arthropathy that most commonly affects the joints in the knees, hands, feet, and spine; it is also relatively common in other joints such as the shoulder and hip joints and potentially affects all synovial joints $[1,2]$. OA is the most common form of arthritis and is a leading cause

Jean-Yves Reginster

jyreginster@ulg.ac.be

1 Division of Public Health, Epidemiology and Health Economics, University of Liège, Liège, Belgium

2 WHO Collaborating Center for Public Health Aspects of Musculoskeletal Health and Aging, University of Liège, Liège, Belgium

3 Chair for Biomarkers of Chronic Diseases, Biochemistry Department, College of Science, King Saud University, Riyadh, Kingdom of Saudi Arabia

4 Geriatric Unit, Department of Internal Medicine and Geriatrics, University of Palermo, 90100 Palermo, Italy of morbidity and chronic disability. Prevalence of OA increases with age: worldwide estimates are that $9.6 \%$ of men and $18.0 \%$ of women over 60 years have symptomatic OA. Eighty percent of people affected by OA experience limitations in movement, and $25 \%$ cannot perform their major daily life activities [3]. The main pathophysiological event is the thinning of cartilage in joints which results in bones rubbing together, causing stiffness, pain, and impaired movement with reduced quality of life and significant social and economic burden $[4,5]$. Although research has focused primarily on the alterations in joint cartilage and synovial film, there is increasing evidence of involvement of all joint tissues [6]. The main goals in OA treatments are to relief pain, to slow the progression of joint structure modifications and to improve functional limitation and quality of life [7,8]. Global strategies aim to reduce the burden of musculoskeletal disease and promote healthy ageing tailored to meet the individual patient's needs [9]. The recent European Society for Clinical and Economic Aspects of Osteoporosis, Osteoarthritis and Musculoskeletal Diseases (ESCEO) guideline for the 
BASIC PRINCIPLE AND CORE SET

Combination of treatment modalities, including non-pharmacological and pharmacological therapies is strongly recommended

Core set: - Information/Education

- Weight loss if overweight

- Exercise program (i.e. aerobic, strengthening, or resistance exercises)

STEP 1: Background treatment
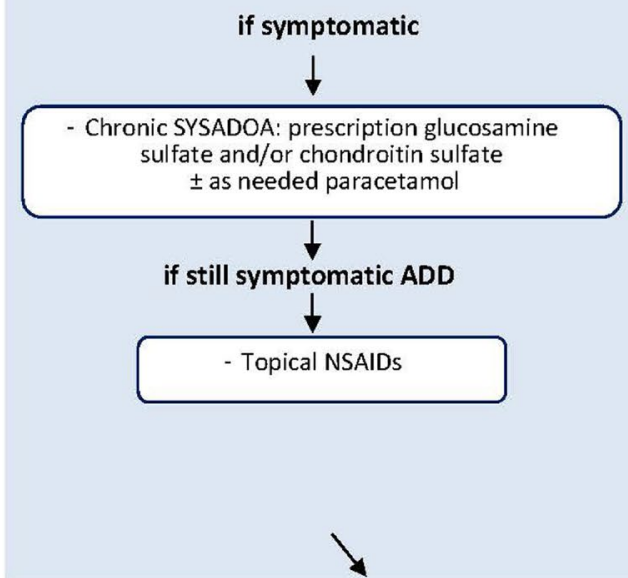

\section{Referral to physical therapist for: if needed} (to control malalignment)

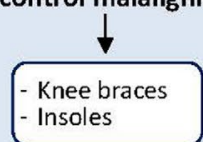

- Insoles

\section{if symptomatic ADDITION at any time}

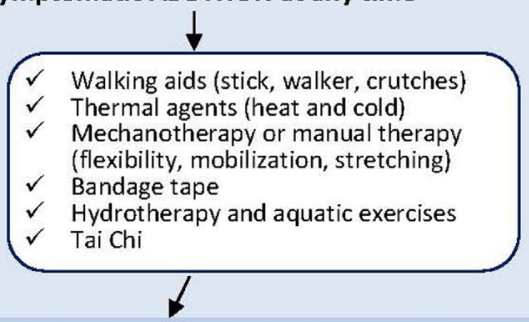

STEP 2: Advanced pharmacological management in the persistent symptomatic patient

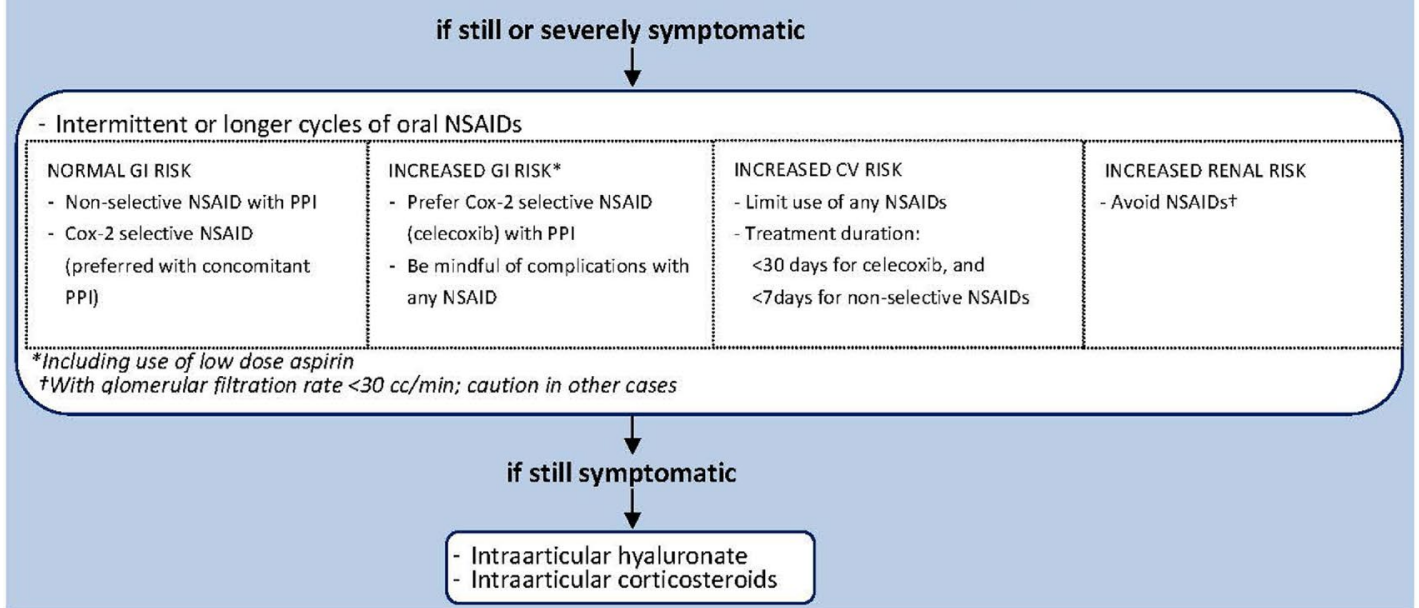

STEP 3: Last pharmacological attempts

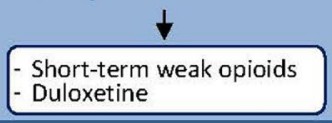

\section{STEP 4: End-stage disease management and surgery}

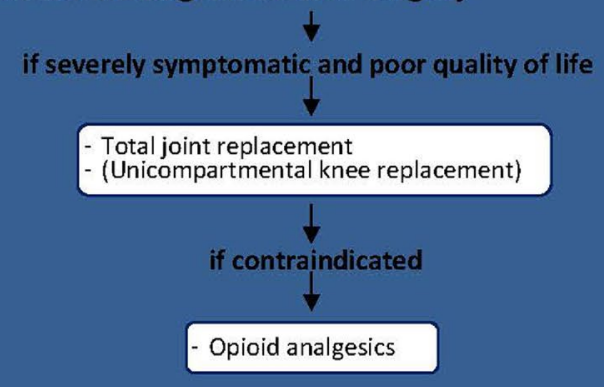


4Fig. 1 Updated ESCEO stepwise treatment algorithm for knee osteoarthritis. COX-2, cyclooxygenase-2; CS, chondroitin sulfate; CV, cardiovascular; GI, gastrointestinal; GS, glucosamine sulfate; IA, intraarticular; NSAID, non-steroidal anti-inflammatory drug; PPI, proton pump inhibitor; SYSADOA, symptomatic slow-acting drugs in osteoarthritis; OA, osteoarthritis. Reproduced from Bruyère et al. [10] with permission from BMJ Publishing Group Ltd

management of OA [10] recommend a combination of non-pharmacologic and pharmacologic measures (Fig. 1).

Fast-acting symptom modifying drugs include traditional analgesics (e.g. paracetamol, tramadol etc.), non-steroidal anti-inflammatory drugs (NSAIDs) and intra-articular corticosteroids. These substances induce a fast relief of symptoms and improve joint function [11]. However, they are not devoid of toxicity and when used chronically their gastrointestinal, liver, kidney and haematological side effects (sometimes serious) can be clinically important and associated to high costs, particularly in the elderly. Slow-acting drugs for the treatment of OA are defined as symptom modifying (Symptomatic Slow Acting Drugs of OA, SYSADOA). This group includes drugs that can be administered systemically (e.g. chondroitin sulfate $\mathrm{CS}$, glucosamine GlcN sulfate, diacerein), as well as substances that can be administered intra-articularly (hyaluronic acid). Chondroitin sulfate oral supplementation is recommended by ESCEO and other European guidelines $[10,12,13]$ as background treatment to reduce joint pain and improve functional impairment in OA patients. Chemically, CS monomer is a disaccharide molecule constituted by $\mathrm{N}$-acetylgalactosamine and glucuronic acid; The sulfate group in CS can be linked to the galactosamine moiety in two positions-4 or 6-which explains the existence of two isomers (Fig. 2).

Chondroitin sulfate is usually derived from bovine, porcine, chicken or fish cartilage sources by extraction and purification procedures. Several clinical studies, as reported in the review by Chevalier and Conrozier [11] the metaanalysis by Hochberg et al. [15], Hochberg [15] and Honvo et al. [16, 17] demonstrated that CS at the marketed unit dose strengths $(400 \mathrm{mg}, 800 \mathrm{mg}$ and $1200 \mathrm{mg}$ ) exerts an important activity on the mitigation of pain caused by OA, particularly knee, hand and hip OA; CS induces an improvement of algo-functional scores with a very low risk of toxicity reported in post-marketing surveillance data.

Considering the important role played by CS in the treatment of OA, we aimed to review the existing evidence on highly purified chondroitin sulfate $(\mathrm{hpCS})$ (Condrosulf $^{\circledR}$ IBSA), a prescription drug containing highly purified chondroitins 4 and 6 sulfate in a concentration not less than $95 \%$. We grouped the evidence by involved joint, adding specific discussion for the new dosage of hpCS $1200 \mathrm{mg}$, for the comparison with food supplements and for pharmacoeconomic aspects.

\section{Materials and methods}

The MEDLINE and PubMed databases were searched for randomized controlled trials (RCTs), meta-analyses, systematic reviews and review articles on hpCS in OA published between 1992 and 2020. The search strategy was based on carefully constructed review questions and was performed using the appropriate clinical terms to identify all papers containing information on hpCS efficacy and safety and to address specific questions relevant to the dosage as well as pharmacoeconomic aspects. PICO evidence-based model [18] was used for framing a question, locating, assessing, evaluating and repeating as needed. PICO keywords are focused on:

- Problem/patient/population: people with osteoarthritis.

- Intervention: chondroitin sulfate.

- Comparison: placebo/no intervention.

- Outcomes: pain and function.

The literature searches included the terms: 'chondroitin sulfate', 'pharmaceutical-grade', 'highly purified', 'osteoarthritis' 'knee osteoarthritis', 'hip osteoarthritis', 'hand osteoarthritis', 'food supplement' 'pharmacoeconomy'. The references of retrieved paper were manually searched for additional relevant articles and guidelines and OA treatment recommendations were also considered.

\section{Pharmacokinetics}

The structure and characteristics of hpCS, such as molecular mass, charge density (in terms of electrostatic properties related to sulfated and nonsulfated disaccharides) and cluster of disulfated disaccharides can strongly influence its absorption and bioavailability. The pharmacokinetic (PK) characteristics of oral hpCS were evaluated in healthy volunteers $[19,20]$. In a study by Conte et al. [20] hpCS was given to 12 healthy volunteers in fasting conditions as a single dose or two $400 \mathrm{mg}$ doses at a 12-h interval. Table 1 summarizes the results of the main PK parameters in this study.

Twenty-four hours after oral administration, a high concentration was found in the intestine, liver and kidneys, organs involved in the breakdown and the excretion of oligoand polysaccharides, but also in the synovial fluid and cartilages, where the molecule tends to accumulate [21, 22].

\section{Pharmacodynamics}

The pharmacodynamics of CS is extensively studied. Bassleer et al. [23] found that in chondrocytes, hpCS antagonizes interleukin-1(IL-1)-induced increases in p38 
Fig. 2 Formula of CS monomer

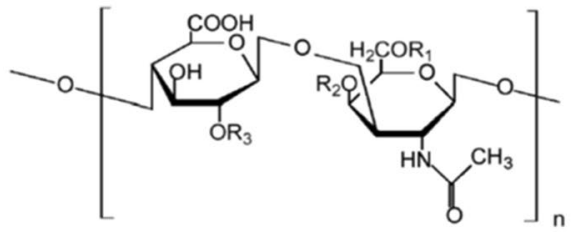

$\mathrm{R} 1=\mathrm{H} ; \mathrm{R} 2=\mathrm{SO} 3 \mathrm{H} ; \mathrm{R} 3=\mathrm{H}$ : Chondroitin-4-sulfate

$\mathrm{R} 1=\mathrm{SO} 3 \mathrm{H} ; \mathrm{R} 2=\mathrm{R} 3=\mathrm{H}$ : Chondroitin-6-sulfate

Table 1 Pharmacokinetic parameters after oral administration of $800 \mathrm{mg}$ hpCS. Modified from Conte et al. [20]

\begin{tabular}{lcc}
\hline PK parameter & $\begin{array}{l}800 \mathrm{mg} \text { single dose } \\
(\text { mean } \pm \mathrm{SD})\end{array}$ & $\begin{array}{c}400 \mathrm{mg}+400 \mathrm{mg} \\
\text { dose }(\text { mean } \pm \mathrm{SD})\end{array}$ \\
\hline$C_{\text {max }}(\mu \mathrm{g} / \mathrm{ml})$ & $2.6 \pm 0.5$ & $1.2 \pm 0.2^{\mathrm{a}}$ \\
$t_{\max }(\mathrm{h})$ & $5.0 \pm 1.0$ & $5.2 \pm 1.0^{\mathrm{a}}$ \\
$t^{1 / 2}(\mathrm{~h})$ & $10.3 \pm 6.8$ & $10.3 \pm 2.5^{\mathrm{b}}$ \\
$\mathrm{AUC}_{0-12 \mathrm{~h}}(\mu \mathrm{g} \mathrm{h} / \mathrm{ml})$ & $23.9 \pm 4.2$ & $10.6 \pm 1.7$ \\
$\mathrm{AUC}_{\infty}(\mu \mathrm{g} \mathrm{h} / \mathrm{ml})$ & $46.8 \pm 10.1$ & $37.3 \pm 9.4$ \\
\hline
\end{tabular}

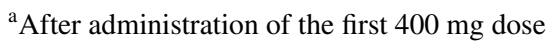

${ }^{\mathrm{b}}$ After administration of the second $400 \mathrm{mg}$ dose

mitogen-activated protein kinase (p38MAPK) and signalregulated kinase 1/2 (Erk1/2) phosphorylation and decreases in nuclear factor-B (NFB) nuclear translocation and as a consequence reduced formation of pro-inflammatory cytokines, IL-1 and TNF, and pro-inflammatory enzymes, such as phospholipase A2 (PLA2), cyclooxygenase 2 (COX-2) and nitric oxide synthase-2 (NOS-2). The mechanism of action of CS explains its beneficial effect on the cartilage, synovial membrane and subchondral bone. In vivo, hpCS given p.o. prevented hepatic NFB nuclear translocation and this suggested that systemic hpCS could elicit an anti-inflammatory effect in many tissues besides the articulation. On this basis, Ronca et al. [24] and Cohen et al. [25] reported that hpCS could be useful also in other inflammatory diseases, like psoriasis and atherosclerosis. Jomphe et al. [26] observed that the beneficial effects of hpCS in patients with OA result partially from its antinflammatory and immunomodulatory actions, as the reduction of NFB nuclear translocation, the decrease in the synthesis of pro-inflammatory cytokines IL- 1 and TNF and in the activity of NOS-2 and COX-2. Other actions of hpCS contribute to its activity, such as the increase in the synthesis of articular cartilage PG, the reduction in the apoptosis of chondrocytes and the reduction of the synthesis and/or activity of MMPs [27-32].

\section{Clinical evidence on highly purified chondroitin sulfate}

Table 2 summarizes the clinical evidence on hpCS in OA, preclinical studies and meta-analyses discussed are not included.

\section{Hip and knee OA}

Conrozier and Vignon [33] in their study on hip OA used eight parameters: (1) Huskisson's Visual Analogue Scale (VAS); (2) Lequesne's Index (LI); (3) analgesic consumption; (4) morning stiffness; (5) walking autonomy; (6) awakenings during the night, (7) intramalleolar distance, (8) patient evaluation. Parameters 1, 2, 3 and 8 were considered as essential. The hpCS group showed a statistically significant improvement compared to the placebo (PLB) in all essential parameters. Figure 3 shows the evolution of pain measured by the VAS.

As for knee OA, Uebelhart et al. [34, 35] conducted a pilot study and a RCT. In the pilot study, hpCS was associated with a stabilization of the medial femorotibial joint space width (JSW). The study evaluated also biomarkers of bone formation (osteocalcin), aggrecan (serum antigentic keratan sulfate) and connective tissue (urinary pridinolyne) degradation. The parameters were stabilized in hpCS patients, whilst they remained abnormal in the PLB group. In the subsequent RCT, LI decreased significantly by $36 \%$ in the hpCS group after 1 year compared to $23 \%$ in the PLB group $(p=0.001)$. Radiological progression at month 12 showed a significant decrease of JSW in the PLB group, whilst there were no changes in the hpCS group $(p<0.05)$. The authors concluded that, in addition to the actions on signs and symptoms, the effect of hpCS on the JSW narrowing provided further evidence of the structure-modifying properties of hpCS in knee OA. In his study, Michel et al. [36] found that 150 patients receiving PLB showed a progressive JSW narrowing, with a mean JSW loss of $0.14 \pm 0.61 \mathrm{~mm}$ after 2 years $(p=0.001)$. The 150 patients treated with hpCS did not show any change in mean JSW $(0.00 \pm 0.53 \mathrm{~mm}$; $p \mathrm{NS})$; the minimum JSW narrowing showed a similar trend. The differences between groups were significant for mean $(0.14 \pm 0.57 \mathrm{~mm} ; p=0.04)$ and minimum JSW $(0.12 \pm 0.52 \mathrm{~mm} ; p=0.05)$. The study demonstrated that hpCS may slow the structural progression of knee OA. In a prospective, open study, Radrigàn et al. [37] observed at day 90 an improvement of $44.4 \%$ in the LI ( $p<0.0001)$ and of $56.8 \%$ (right) and $61.7 \%$ (left) in the knee pain measured by VAS. At day 180 (90 days after the last administration of hpCS) the parameters were still significantly better than the basal levels. The residual effect was more marked in patients $<65$ years and in those with less basal radiological damage. Kahan et al. [38] studied 
Table 2 Clinical studies on hpCS in Hip, Knee and Hand OA, on formulation $1200 \mathrm{mg} / \mathrm{die}$ and on pharmacoeconomic impact

\begin{tabular}{|c|c|c|c|}
\hline $\begin{array}{l}\text { Condition/topic } \\
\text { First author [Ref.] } \\
\text { Design }\end{array}$ & Patients & $\begin{array}{l}\text { Treatment/dose } \\
\text { Control/dose } \\
\text { Follow-up }\end{array}$ & Summary of results, primary efficacy parameters \\
\hline \multicolumn{4}{|l|}{ Hip $O A$} \\
\hline $\begin{array}{l}\text { Conrozier } 1992[33] \\
\text { RCT }\end{array}$ & 56 & $\begin{array}{l}\text { hpCS } 3 \times 400 \mathrm{mg} / \text { day } \\
\text { PLB } \\
6 \text { months }\end{array}$ & $\begin{array}{l}\text { Pain (VAS); LI; analgesic consumption; patient's assessment, } \\
\text { hpCS better than PLB }\end{array}$ \\
\hline \multicolumn{4}{|l|}{ Knee $O A$} \\
\hline $\begin{array}{l}\text { Uebelhart } 1998[34] \\
\text { RCT pilot }\end{array}$ & 42 & $\begin{array}{l}\text { hpCS } 800 \mathrm{mg} / \text { day } \\
\text { PLB } \\
1 \text { year }\end{array}$ & $\begin{array}{l}\text { Pain and overall mobility (VAS) at } 3(p<0.05) \text { and } 12 \\
(p<0.01) \text { months hpCS better than PLB }\end{array}$ \\
\hline $\begin{array}{l}\text { Uebelhart } 2004 \text { [35] } \\
\text { RCT }\end{array}$ & 120 & $\begin{array}{l}\text { hpCS } 800 \mathrm{mg} / \text { day } \\
\text { PLB } \\
2 \times 3 \text { months during } 1 \text { year }\end{array}$ & $\begin{array}{l}\text { hpCS: more LI decrease }(36 \% \text { hpCS vs } 23 \% \text { PLB; } \\
p=0.001) \text {; less JSW reduction }(0.44 \text { vs } 0.46 \mathrm{~mm} p<0.05) \\
\text { than PLB }\end{array}$ \\
\hline $\begin{array}{l}\text { Michel } 2005[36] \\
\text { RCT }\end{array}$ & 300 & $\begin{array}{l}\text { hpCS } 800 \mathrm{mg} / \text { day } \\
\text { PLB } \\
2 \text { years }\end{array}$ & $\begin{array}{l}\text { JWS at } 2 \text { years: hpCS no change; PLB }-0.14 \mathrm{~mm},(p<0.001 \\
\text { vs. baseline) }\end{array}$ \\
\hline $\begin{array}{l}\text { Radrigàn } 2007 \text { [37] } \\
\text { Open, non-controlled }\end{array}$ & 61 & $\begin{array}{l}\text { hpCS } 800 \mathrm{mg} / \text { day for } 3 \text { months } \\
\text { follow-up: } 6 \text { months }\end{array}$ & $\begin{array}{l}\text { Improvement of } 44.4 \% \text { in the LI ( } p<0.0001) \text { and of } 56.8 \% \\
\text { (right) and } 61.7 \% \text { (left) in the knee pain measured by VAS }\end{array}$ \\
\hline $\begin{array}{l}\text { Kahan } 2009 \text { [38] } \\
\text { RCT }\end{array}$ & 622 & $\begin{array}{l}\text { hpCS } 800 \mathrm{mg} / \text { day } \\
\text { PLB } \\
2 \text { years }\end{array}$ & $\begin{array}{l}\text { Reduction in JSW loss with hpCS }(p<0.0001 \text { vs. PLB); } \\
\text { less patients with radiographic progression in hpCS } \\
(p<0.0005)\end{array}$ \\
\hline $\begin{array}{l}\text { Möller } 2010 \text { [39] } \\
\text { RCT }\end{array}$ & 129 & $\begin{array}{l}\text { hpCS } 800 \mathrm{mg} / \text { day } \\
\text { PLB } \\
3 \text { months }\end{array}$ & $\begin{array}{l}\text { hpCS better than PLB in pain at VAS }(p<0.01) \text {, LI }(p<0.05) \\
\text { reduction of use of analgesics }(p<0.05)\end{array}$ \\
\hline $\begin{array}{l}\text { Wildi } 2011[40] \\
\text { RCT }\end{array}$ & 69 & $\begin{array}{l}\text { hpCS } 800 \mathrm{mg} / \text { day } \\
\text { PLB } \\
6 \text { months double- blind } \\
\text { hpCS } 800 \mathrm{mg} / \text { day } \\
6 \text { months open-label }\end{array}$ & $\begin{array}{l}\text { Less cartilage volume loss in hpCS than in PLB group } \\
(p=0.03) \text {. Lower subchondral BML scores in hpCS group } \\
\text { at } 12 \text { months (lateral compartment } p=0.035 \text {; lateral con- } \\
\text { dyle } p=0.044)\end{array}$ \\
\hline $\begin{array}{l}\text { Montfort } 2012[41] \\
\text { RCT }\end{array}$ & 45 & $\begin{array}{l}\mathrm{hpCS} 800 \mathrm{mg} / \text { day } \\
\text { paracetamol } 4000 \mathrm{mg} / \text { day } \\
6 \text { months }\end{array}$ & $\begin{array}{l}\text { hpCS significantly reduced synovitis compared to paraceta- } \\
\text { mol }(p<0.01) \\
\text { hpCS effectively reduced functional incapacity }(p<0.01)\end{array}$ \\
\hline $\begin{array}{l}\text { Reginster } 2017 \text { [42] } \\
\text { RCT }\end{array}$ & 604 & $\begin{array}{l}\text { hpCS } 800 \mathrm{mg} / \text { day } \\
\text { celecoxib } 200 \mathrm{mg} / \text { day } \\
\text { PLB } \\
6 \text { months }\end{array}$ & $\begin{array}{l}\text { At day } 182 \text { pain (VAS) reduced ( } p=0.001 \mathrm{hpCS} ; p=0.009 \\
\text { celecoxib) and LI reduced ( } p=0.023 \mathrm{hpCS} ; p=0.015 \\
\text { celecoxib) vs. PLB }\end{array}$ \\
\hline \multicolumn{4}{|l|}{ Hand $O A$} \\
\hline $\begin{array}{l}\text { Wang } 1992[43] \\
\text { RCT }\end{array}$ & 34 & $\begin{array}{l}\text { hpCS } 3 \times 400 / \text { day } \\
\text { PLB } \\
18 \text { months }\end{array}$ & hpCS reduced pain (VAS) and improved hand function \\
\hline $\begin{array}{l}\text { Verbruggen } 1998 \text { [44] } \\
\text { RCT }\end{array}$ & 119 & $\begin{array}{l}\text { hpCS } 3 \times 400 \mathrm{mg} / \text { day } \\
\text { PLB } \\
3 \text { years }\end{array}$ & $\begin{array}{l}\text { Patients with new joints with lesions: hpCS 5.9\%; PLB } \\
22.4 \%\end{array}$ \\
\hline $\begin{array}{l}\text { Rovetta } 2002[45] \\
\text { RCT }\end{array}$ & 24 & $\begin{array}{l}\text { hpCS } 800 \mathrm{mg} / \text { day + naproxen } 500 \mathrm{mg} / \text { day } \\
\text { naproxen } 500 \mathrm{mg} / \text { day } \\
24 \text { months }\end{array}$ & $\begin{array}{l}\text { hpCS + naproxen lower increase in number of joints with ero- } \\
\text { sions }(p<0.05)\end{array}$ \\
\hline $\begin{array}{l}\text { Rovetta } 2004[46] \\
\text { RCT }\end{array}$ & 24 & $\begin{array}{l}\text { hpCS } 800 \mathrm{mg} / \text { day + naproxen } 500 \mathrm{mg} / \text { day } \\
\text { naproxen } 500 \mathrm{mg} / \text { day } \\
24 \text { months }\end{array}$ & $\begin{array}{l}\text { hpCS + naproxen better than naproxen in Heberden } \\
(p<0.001) \text { and Dreiser }(p<0.001) \text { scores, in patient's } \\
(p<0.001) \text { and clinician's }(p<0.001) \text { judgement }\end{array}$ \\
\hline $\begin{array}{l}\text { Gabay } 2011[47] \\
\text { RCT }\end{array}$ & 162 & $\begin{array}{l}\text { hpCS } 800 \mathrm{mg} / \text { day } \\
\text { PLB } \\
6 \text { months }\end{array}$ & $\begin{array}{l}\text { Significant decrease in the patient's global assessment of } \\
\text { hand pain (difference VAS scores }-8.7 \mathrm{~mm} ; p=0.016) \\
\text { and significant improvement in FIHOA score }(-2.14 ; \\
p=0.008 \text { ) in hpCS group vs placebo }\end{array}$ \\
\hline
\end{tabular}


Table 2 (continued)

\begin{tabular}{|c|c|c|c|}
\hline $\begin{array}{l}\text { Condition/topic } \\
\text { First author [Ref.] } \\
\text { Design }\end{array}$ & Patients & $\begin{array}{l}\text { Treatment/dose } \\
\text { Control/dose } \\
\text { Follow-up }\end{array}$ & Summary of results, primary efficacy parameters \\
\hline \multicolumn{4}{|l|}{$\begin{array}{l}\text { Condrosulf } 1200 \mathrm{mg} \\
\text { Knee OA }\end{array}$} \\
\hline $\begin{array}{l}\text { Morreale } 1996[48] \\
\text { RCT }\end{array}$ & 146 & $\begin{array}{l}\text { hpCS } 3 \times 400 \mathrm{mg} / \mathrm{day} \\
\text { diclofenac } 3 \times 50 \mathrm{mg} / \text { day; } \\
3 \text { months }+3 \text { months follow-up }\end{array}$ & $\begin{array}{l}\text { LI hpCS }-64.4 \% \text {; diclofenac vs }-29.7 \% \text { vs baseline; par- } \\
\text { acetamol consumption hpCs }-88 \% \text {; diclofenac }-37.8 \% \\
(p<0.01)\end{array}$ \\
\hline $\begin{array}{l}\text { Bourgeois } 1998 \text { [49] } \\
\text { RCT }\end{array}$ & 127 & $\begin{array}{l}\text { hpCS gel } 1 \times 1200 \mathrm{mg} / \text { day } \\
\text { hpCS } 3 \times 400 \mathrm{mg} / \text { day } \\
\text { PLB } \\
3 \text { months }\end{array}$ & $\begin{array}{l}\text { hpCS } 1 \times 1200 \text { and } 3 \times 400 \text { lower than PLB in LI }(p<0.0001 \\
\text { at day } 91) \text { and pain }(\text { VAS })(\text { hpCS } 1 \times 1200 p<0.01 \text { from } \\
\text { day } 14 \text {; hpCS } 3 \times 400 p<0.005 \text { from day } 42)\end{array}$ \\
\hline $\begin{array}{l}\text { Pavelka } 1998 \text { [50] } \\
\text { RCT }\end{array}$ & 140 & $\begin{array}{l}\text { hpCS } 200 \mathrm{mg} / \mathrm{die} \\
2 \times 400 \mathrm{mg} / \mathrm{die} \\
3 \times 400 \mathrm{mg} / \mathrm{die} \\
\mathrm{PLB} \\
3 \text { months }\end{array}$ & $\begin{array}{l}\text { hpCS } 2 \times 400 \text { and } 3 \times 400 \mathrm{mg} / \text { die more effective than } \\
200 \mathrm{mg} / \mathrm{die} \text { and PLB on LI }(p<0.01) \text {; pain at VAS } \\
(p<0.01) \text {. No difference between } 2 \times 400 \text { and } 3 \times 400 \mathrm{mg} / \\
\text { day }\end{array}$ \\
\hline $\begin{array}{l}\text { Clegg } 2006[51] \\
\text { RCT }\end{array}$ & 1583 & $\begin{array}{l}\text { hpCS } 3 \times 400 \mathrm{mg} / \text { day } \\
\text { GlcN } 3 \times 500 \mathrm{mg} / \text { day } \\
\text { GlcN }+ \text { hpCS } \\
\text { celecoxib } 200 \mathrm{mg} / \text { day } \\
\text { PLB } \\
2 \text { years }\end{array}$ & $\begin{array}{l}\text { Response rate, percent difference from PLB } \\
\text { GlcN }+3.9 \%(p=0.30) \\
\text { hpCS: }+5.3 \%(p=0.17) \\
\text { GlcN }+ \text { hpCS: } \% 6.5 \%(p=0.09) \\
\text { celecoxib: }+10.0 \%(p=0.008)\end{array}$ \\
\hline $\begin{array}{l}\text { Zegels } 2013 \text { [52] } \\
\text { RCT }\end{array}$ & 353 & $\begin{array}{l}\mathrm{hpCS} 1 \times 1200 \mathrm{mg} / \text { day } \\
3 \times 400 \mathrm{mg} / \text { day } \\
\mathrm{PLB}\end{array}$ & $\begin{array}{l}\text { hpCS } 1200 \mathrm{mg} \text { or hpCS } 3 \times 400 \mathrm{mg} / \text { day significantly } \\
\text { improved compared to PLB in terms of LI }(p<0.001) \text { and } \\
\text { VAS for spontaneous pain }(p<0.01)\end{array}$ \\
\hline $\begin{array}{l}\text { Pelletier } 2016[53] \\
\text { RCT }\end{array}$ & 114 & $\begin{array}{l}\text { hpCS } 3 \times 400 \mathrm{mg} / \text { day } \\
\text { celecoxib } 200 \mathrm{mg} / \text { day } \\
2 \text { years }\end{array}$ & $\begin{array}{l}\text { hpCS showed less cartilage loss than celecoxib in medial } \\
\text { compartment }(p=0.018) \text { and medial condyle }(p=0.008)\end{array}$ \\
\hline $\begin{array}{l}\text { IBSA } 2019 \\
\text { RCT }\end{array}$ & 246 & $\begin{array}{l}\text { hpCS } 1 \times 1200 \mathrm{mg} / \text { day } \\
\text { hpCS } 3 \times 400 \mathrm{mg} / \text { day } \\
91 \text { days }\end{array}$ & $\begin{array}{l}\text { hpCS } 1200 \mathrm{mg} \text { once daily not inferior to hpCS } 3 \times 400 \mathrm{mg} / \\
\text { day in LI }(-2.9 \pm 0.3 ;-2.6 \pm 0.3 \text {, respectively; } \\
p<0.0001) \text {. No significant difference regarding pain, } \\
\text { NSAIDs consumption }\end{array}$ \\
\hline $\begin{array}{l}\text { IBSA } 2019 \\
\text { RCT }\end{array}$ & 94 & $\begin{array}{l}\text { hpCS } 1 \times 1200 \mathrm{mg} / \text { day } \\
\text { hpCS } 3 \times 400 \mathrm{mg} / \text { day } \\
\text { PLB } \\
91 \text { days }\end{array}$ & $\begin{array}{l}\text { Mean }( \pm \text { SD) decrease of LI from baseline to day } 91:-4.3 \\
\text { (3.3) in the hpCS } 1200 \mathrm{mg} \text { group, }-4.1(2.9) \text { in the hpCS } \\
400 \mathrm{mg} \text { group and }-1.0(2.0) \text { in the PLB group }\end{array}$ \\
\hline \multicolumn{4}{|l|}{ Pharmacoeconomy } \\
\hline $\begin{array}{l}\text { Bruyère } 2009[58] \\
\text { Knee OA } \\
\text { RCT }\end{array}$ & 622 & $\begin{array}{l}\text { hpCS } 800 \mathrm{mg} / \mathrm{die} \\
\text { PLB } \\
2 \text { years }\end{array}$ & $\begin{array}{l}\text { Health Utility Index better for hpCS than PLB at } 6 \text { months } \\
(p<0.03)\end{array}$ \\
\hline $\begin{array}{l}\text { Lagnaoui } 2006[59] \\
\text { OA } \\
\text { Prospective observational }\end{array}$ & 844 & $\begin{array}{l}\text { hpCS } 800-1200 \mathrm{mg} / \text { day } \\
\text { Long-term }(\geq 3 \text { months }) \\
\text { Recent ( }<3 \text { months }) \text { users }\end{array}$ & $\begin{array}{l}\text { Lower consumption of NSAIDs }(p<0.05) \text { and analgesics } \\
(p<0.01) \text { by long-term users }\end{array}$ \\
\hline $\begin{array}{l}\text { Rubio-Terres } 2010[4] \\
\text { OA } \\
\text { Observational retrospective }\end{array}$ & 530 & $\begin{array}{l}\text { CS } \\
\text { NSAIDs } \\
\text { CS + NSAIDs } \\
\text { 6-months }\end{array}$ & $\begin{array}{l}\text { Treatment cost 6-month: CS } € 141 \text {; NSAIDs } € 182 \text {. Concomi- } \\
\text { tant CS could reduce use of NSAIDs }\end{array}$ \\
\hline
\end{tabular}

the effects of hpCS on the progression of knee OA. The hpCS group had a reduced loss of minimum JSW compared with the PLB group $(-0.07 \pm 0.03 \mathrm{~mm}$ vs $-0.31 \pm 0.04 \mathrm{~mm}$ $p<0.0001)$. The percentage of patients with radiographic progression $>0.25 \mathrm{~mm}$ was lower in the hpCS than in PLB group [ $28 \%$ vs $41 \%(p<0.0005)$; with a relative risk reduction of $33 \%(95 \%$ CI 16-46\%)]. The number of patients needed to treat was eight (95\% CI 5-17). Pain improved faster in the hpCS than in the PLB group $(p<0.01)$.
Möller et al. [39] found that after 3 months hpCS resulted more effective than PLB, relieving pain at VAS (hpCS $-26.9 \pm 24.8$; PLB $-14.23 \pm 20.8 \mathrm{~mm}, p<0.01)$, decreasing the LI (hpCS $-4.8 \pm 3.4$; PLB $-3.3 \pm 3.5, p<0.05)$ and reducing the use of paracetamol as rescue medication (hpCS 43\%; PLB 64\%, $p<0.05$ ). hpCS improved also signs of plantar psoriasis more than PLB (hpCS $87 \%$; PLB $27 \%, p<0.05)$. In the RCT by Wildi et al. [40], hpCS group showed significantly less cartilage volume loss than 
Fig. 3 Reduction of pain in hip measured by a VAS scale; ${ }^{*} p<0.01, * * p<0.001$, NS Not Significant; drawn based on data reported in Conrozier and Vignon [33]
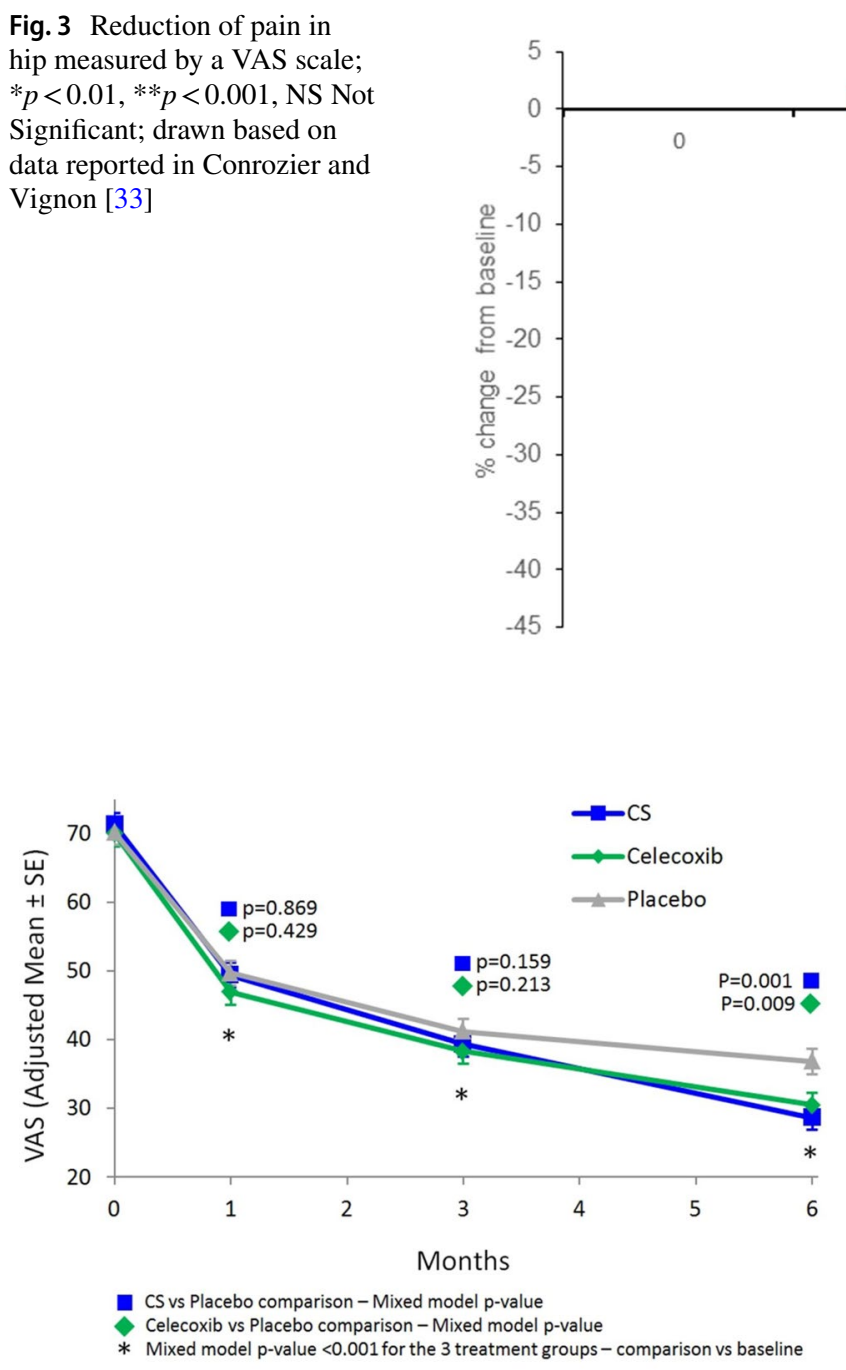

Fig. 4 Reduction of pain in knee measured by a VAS scale. Reproduced from Reginster et al. [42] with permission from Elsevier

the PLB group as early as 6 months for the global knee $(p=0.030)$, the lateral compartment $(p=0.015)$ and tibial plateaus $(p=0.002)$. The difference remained significant at 12 months. Significantly lower subchondral bone marrow lesions scores were found for the hpCS group at 12 months in the lateral compartment $(p=0.035)$ and the lateral femoral condyle $(p=0.044)$. Montfort [41] focused his study on synovitis. HpCS but not paracetamol reduced synovitis and symptoms in OA patients. The study showed also a decrease in synovial and plasma levels of inflammatory chemokines in hpCS group. In his RCT, Reginster et al. [42] observed that hpCS and celecoxib showed a significant reduction in pain and LI compared with PLB. In the intention-to-treat (ITT) population, pain reduction at VAS at day 182 was significantly greater in the hpCS group $(-42.6 \mathrm{~mm})$ and in the celecoxib group $(-39.5 \mathrm{~mm})$ than in PLB group $(-33.3 \mathrm{~mm}$, $p=0.001$ hpCS; $p=0.009$ celecoxib), without difference

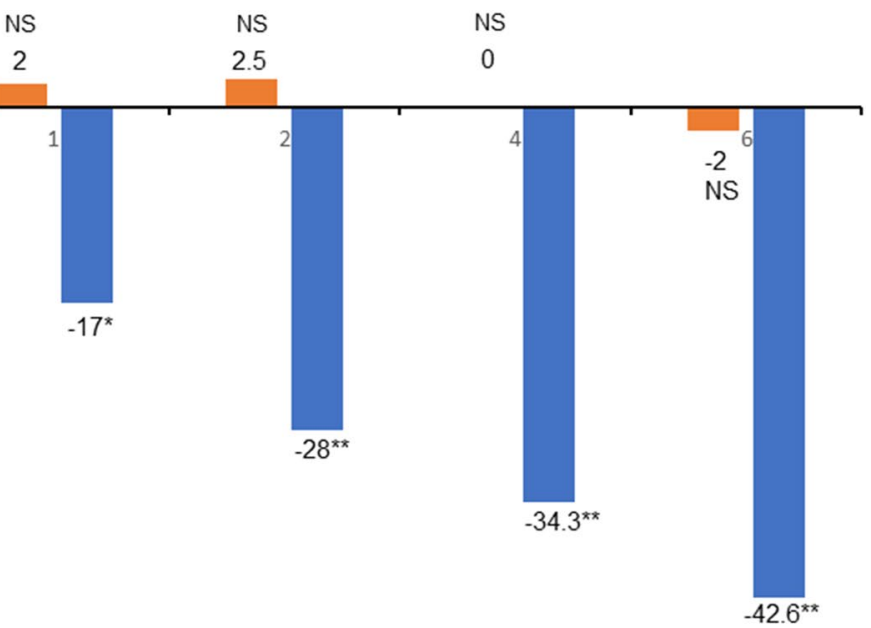

Months

$\because \mathrm{PLB} \| \mathrm{CS}$

between hpCS and celecoxib (Fig. 4). The improvement of LI was greater in the hpCS $(-4.7)$ and celecoxib $(-4.6)$ than in the PLB group $(-3.7)(p=0.023$ for HPCS; $p=0.015$ for celecoxib). No difference was observed between hpCS and celecoxib. The secondary endpoints: Minimal-Clinically Important Improvement (MCII) and Patient-Acceptable Symptoms State (PASS), showed significant improvement in the hpCS and celecoxib groups compared to PLB.

\section{Hand OA}

Wang et al. [43] on 34 patients found that the treatment with hpCS reduced pain and improved function of the hand without impact on radiological signs. In the RCT by Verbruggen et al. [44], hpCS group reported a significant decrease in the number of patients with new erosive OA lesions in the finger joints. In two RCTs, Rovetta et al. [45, 46] observed a significant difference in favour of the hpCS + naproxen group compared to naproxen only in number of joints with erosions $(p<0.05)$, a superiority of hpCS in Heberden $(p<0.001)$ and Dreiser $(p<0.001)$ scores and in patient's $(p<0.001)$ and clinician's $(p<0.001)$ judgement. Gabay et al. [47] found that, compared with PLB, patients treated with hpCS showed a significant decrease in the patient's global assessment of pain (difference VAS scores $-8.7 \mathrm{~mm} ; p=0.016$ ). The hpCS group showed also a significant improvement in Functional Index for Hand OsteoArthritis (FIHOA) score $(-2.14 ; p=0.008)$, in morning stiffness and in the investigator's global impression of efficacy.

\section{Condrosulf $1200 \mathrm{mg} /$ day}

The recommended dose of hpCS is $800 \mathrm{mg} /$ day; yet in the most severe cases an initial dose of $1200 \mathrm{mg} /$ day is advisable for the first weeks of treatment, which is then followed 
by a reduction of the dose to $800 \mathrm{mg}$. Morreale et al. [48], comparing hpCS with diclofenac observed that diclofenac had a faster effect, but the treatment with hpCS $3 \times 400 \mathrm{mg} /$ day was associated with longer-lasting symptomatic efficacy, with a lower LI from day 60 to day 180. Bourgeois et al. [49] found that the physician's and patient's overall efficacy assessments were superior for hpCS than PLB $(p<0.001)$. The efficacy of hpCS 1200 oral gel mg once daily did not differ from that of hpCS $3 \times 400 \mathrm{mg} /$ day. Pavelka et al. [50] studied three dosages of hpCS and found that hpCS at 800 and $1200 \mathrm{mg} /$ day was more effective than PLB without difference between the two doses, whilst hpCS $200 \mathrm{mg} /$ day was not different form PLB. Clegg et al. [51] reported that hpCS and GlcN, alone or in combination, had a modest effect on pain reduction compared to PLB, which was associated with a high rate of response. Despite the marked PLB effect, the response rate to hpCS in monotherapy was 5.3\% points higher than PLB. In the RCT by Zegels et al. [52], after 3 months, no significant difference was observed between hpCS $1200 \mathrm{mg}$ oral gel once daily and hpCS $3 \times 400 \mathrm{mg} /$ day. Patients treated with hpCS $1 \times 1200 \mathrm{mg} /$ day or $3 \times 400 \mathrm{mg} /$ day significantly improved compared to PLB in terms of LI $(p<0.001)$ and VAS for spontaneous pain $(p<0.01)$. Pelletier et al. [53] demonstrated that hpCS was superior than celecoxib in reduction of cartilage volume loss measured by magnetic resonance. HpCS and celecoxib were similarly effective in improving joint effusion and/or swelling, WOMAC total score, WOMAC pain score, pain assessed by VAS and quality of life (Short Form-36). Two phase III, multicenter RCTs (IBSA, data on file) evaluated the efficacy and safety of hpCS $1200 \mathrm{mg}$ oral gel once daily vs hpCS $3 \times 400 \mathrm{mg} /$ day. The first study showed that hpCS $1200 \mathrm{mg}$ once daily was not inferior to hpCS $3 \times 400 \mathrm{mg} /$ day in LI $(-2.9 \pm 0.3 ;-2.6 \pm 0.3$, respectively; $p<0.0001)$. No significant difference between groups was observed regarding pain, NSAIDs consumption or patient and investigator global assessment of efficacy. The second study confirmed these evidences. The improvement in LI and the decrease in pain were significantly greater in both hpCS groups compared to PLB, without differences between the two hpCS formulations.

\section{Safety}

The overall analysis of all the studies included in this review, provided evidence that hpCS formulations have a good safety profile. The incidence and severity of hpCS-related adverse events (AEs) are low and similar to those of the placebo also at the dosage of $1200 \mathrm{mg} /$ day. Gastrointestinal disorders were the most common AEs and were reported more in patients of the PLB group than in those of the two hpCS groups with statistically significant differences. Both patients and investigators expressed an excellent/good opinion of safety in the vast majority of cases. These data are consistent with the worldwide post-marketing data from Europe, Middle East, North and South America since 1982 (IBSA data on file).

\section{Chondroitin sulfate versus food supplements}

Food supplements (FS) do not undergo the strict quality controls of pharmaceuticals, because of loose regulatory constraints; this raises concerns about their safety and clinical efficacy. As stated in the position paper endorsed by ESCEO [54], only pharmaceutical CS is shown to deliver consistently high CS bioavailability and plasma concentration in humans, which corresponds to demonstrated clinical efficacy. Volpi and Maccari [55] assessed the amount, quality and origin of CS from ten Czech Republic FS preparations. Only four of the ten preparations met the label specifications. Other four preparations contained between 0 and $1 \%$ CS in comparison with the contents declared on the label $(47 \%, 17 \%, 12 \%, 6 \%)$. Two preparations had $30-45 \%$ of the declared content of CS, and one contained approximately $2 \%$ HA. The CS contained in eight FS was bovine or porcine, in one preparation CS derived from cartilaginous fish and in one case CS levels were too low for any determination.

Restaino et al. [56] examined 25 FS preparations from eight European countries by multiple analytical methods (high performance chromatography, nuclear magnetic resonance, capillary electrophoresis) and biological assays (action on chondrocyte culture). The FS were then compared to two pharmaceutical CS products. Compared to the pharmaceutical-grade products, FS contained low-quality $\mathrm{CS}$, in some cases of multiple animal origins and of dishomogeneous molecular weights. The FS resulted to be highly contaminated by keratan sulfate; the presence of high insoluble solids and solvent residues was suggestive of poorly controlled manufacturing procedures or low-quality raw materials used in the FS preparations. Stellavato et al. [57] assessed the purity, the titer, and the origin of ten different FSs containing CS and then compared their biological activity with two pharmaceutical CS products. The pharmaceutical-grade products demonstrated an effective modulation of biomarkers counteracting the inflammation status and improving viability and the physiological condition of OA human primary chondrocytes and synoviocytes. In contrast, most FSs were cytotoxic at the tested concentrations, and only three out of ten FSs had an in vitro behaviour similar to that of the pharmaceutical-grade products.

The results of the above mentioned researches demonstrate the need for stricter rules to control the quality of FSs to obtain safe and effective products. 


\section{Pharmacoeconomy}

HpCS was comprehensively studied from the pharmacoeconomic point of view. Bruyère et al. [58] in a 2-year RCT, evaluated the impact of hpCS on health-related quality of life using utility values in patients with knee OA. The Health Utility Index (HUI) score changes from baseline to 6 months were $0.02 \pm 0.02$ and $0.05 \pm 0.01$ for the PLB and hpCS groups, respectively ( $p=0.03$ ). After 24 months, the HUI score increased by $0.04 \pm 0.02$ in the PLB group and $0.05 \pm 0.02$ in the hpCS group $(p=0.37)$. Considering the price of hpCS in Europe, the cost effectiveness ratio assessment always resulted in a cost below $€ 30,000$ per qualityadjusted-life-year (QALY) gained, after 6, 12 and 24 months of treatment. Lagnaoui et al. [59] studied the impact of the use of hpCS $400 \mathrm{mg}$ on the consumption of analgesics and NSAIDs. Patients with OA (844) OA were divided in "recent hpCS users" ( $\leq 30$ days of continuous use; 222 pat.) and "long-term hpCS users" ( $>30$ days of continuous use; 622 pat). Ninety-eight (11.6\%) patients did not use any analgesic or NSAIDs; $746(88.4 \%)$ reported the use of at least one of these drugs. Compared to recent users, long-term users of hpCS400 had a significantly lower current (44.4 vs. $52.5 \%, p<0.05)$ and long-term use of NSAIDs $(11.8 \%$ versus $18.5 \%, p<0.05)$ and of analgesics $(70.3$ versus $79.3 \%$, $p<0.01$ ). The results suggested that the use of hpCS could reduce the consumption of NSAIDs. The retrospective study conducted by Rubio-Terrés [4] (data from the VECTRA study) evaluated the economic impact of the treatment with hpCS or NSAIDs. The use of hpCS in 530 patients with OA for more than 6 months reduced the use of NSAIDs. The overall 6-month cost per patient was $141 €$ for CS and $182 €$ for NSAIDs. The authors estimated that in 3 years a gradual shift to hpCS of $5 \%, 10 \%$, and $15 \%$ of patients currently treated with NSAIDs could generate $38,700,000 €$ savings for the Spanish National Health System. In addition, the authors calculated that, for every 10,000 patients switching from NSAIDs to hpCS 2666 cases of gastrointestinal AEs (including $90 \mathrm{SAE}$ ) could be avoided.

\section{Discussion}

This paper provides an updated and comprehensive overview of efficacy, safety, quality and health economics impact of the treatment with hpCS $\left(\right.$ Condrosulf ${ }^{\circledR}$, IBSA). In addition to this, unpublished efficacy data on the new formulation oral gel $1200 \mathrm{mg}$ once daily are presented. The main limit of the paper lies in the different design, size and assessment measures (e.g. radiological techniques) of individual trials; especially the methods of older studies were hampered by the period of their publication. The review of the scientific literature has raised some points that in our opinion deserve further investigation: characteristics of the structural progression of the disease and the most appropriate methods to assess and quantify it; the role of the treatment with hpCS combined with other SYSADOAs (e.g. intra-articular hyaluronic acid) or NSAIDs; biomarkers or predictors of response to treatment with hpCS.

\section{Conclusion}

Highly purified CS, at $400 \mathrm{mg}, 800 \mathrm{mg}$ and $1200 \mathrm{mg}$ was extensively studied. It proved to be safe and effective in hip, knee and hand OA, acting on signs, symptoms and structural changes. The use of hpCS reduced the use of NSAIDs and their side effects. Furthermore, the use of hpCS was found to be cost-effective up to a period of 24 months. It is also important to point out that the quality of hpCS is the prerequisite for safe and effective preparations.

Acknowledgements Dr. Salvatore Bianco of AKROS BioScience (Pomezia, Italy) provided medical writing and editing services during the preparation of the paper.

Author contributions J-YR had the idea for the article and together with NV supervised the literature search and critically revised the work.

Funding The cost of publication of the present review is supported by a non-conditioning contribution by IBSA.

\section{Compliance with ethical standards}

Conflict of interest Dr. Reginster reports grants and personal fees from IBSA-GENEVRIER, grants and personal fees from MYLAN, grants and personal fees from RADIUS HEALTH, personal fees from PIERRE FABRE, personal fees from FAES PHARMA, personal fees from REJUVENATE BIOMED, personal fees from SAMUMED, personal fees from TEVA, personal fees from THERAMEX, personal fees from PFIZER, personal fees from MITHRA PHARMACEUTICALS, grants and personal fees from CNIEL, personal fees from DAIRY RESEARCH COUNCIL (DRC), personal fees from NUTRICIA, personal fees from DANONE, personal fees from AGNOVOS, grants from TRB, outside the submitted work. Dr. Veronese reports personal fees from IBSA, during the conduct of the study; personal fees from Mylan, personal fees from Fidia, outside the submitted work.

Statement of human and animal rights For this specific review article, no novel, original human participant or animal studies were performed.

Ethical approval Not applicable.

Informed consent to participate and for publication Not applicable.

Permissions Permission from the copyright owner(s) of the following figures was obtained, as indicated in figure captions: Figure 1 Licence Nr. 4818901301799, issued on Apr 30, 2020; Reproduced from Bruyère et al. [10] with permission from BMJ Publishing Group Ltd. Figure 3 Licence nr. 4821870178524, issued on May 04, 2020; Reproduced from Reginster et al. [34] with permission from Elsevier.

Code availability Not applicable. 
Statements forms The original forms filled by the authors on conflict of interest/competing interests are available on request.

Open Access This article is licensed under a Creative Commons Attribution 4.0 International License, which permits use, sharing, adaptation, distribution and reproduction in any medium or format, as long as you give appropriate credit to the original author(s) and the source, provide a link to the Creative Commons licence, and indicate if changes were made. The images or other third party material in this article are included in the article's Creative Commons licence, unless indicated otherwise in a credit line to the material. If material is not included in the article's Creative Commons licence and your intended use is not permitted by statutory regulation or exceeds the permitted use, you will need to obtain permission directly from the copyright holder. To view a copy of this licence, visit http://creativecommons.org/licenses/by/4.0/.

\section{References}

1. Neogi T (2014) The epidemioloy and impact of pain in osteoarthritis. Osteoarthr Cartil 21:1145-1153. https://doi. org/10.1016/j.joca.2013.03.018

2. Centers for Disease Control and Prevention. Osteoarthritis. https ://www.cdc.gov/arthritis/basics/osteoarthritis.htm. Accessed 19 Mar 2020

3. World Health Organization (2020) Chronic rheumatic conditions. https://www.who.int/chp/topics/rheumatic/en/. Accessed 15 June 2020

4. Rubio-Terrés C, Grupo del estudio VECTRA (2010) An economic evaluation of chondroitin sulfate and non-steroidal anti-inflammatory drugs for the treatment of osteoarthritis. Data from the VECTRA study. Reumatol Clínica (English Ed) 6:187-195. https://doi.org/10.1016/s2173-5743(10)70043-5

5. Rabenda V, Manette C, Lemmens R et al (2006) Direct and indirect costs attributable to osteoarthritis in active subjects. $\mathrm{J}$ Rheumatol 33:1152-1158

6. Poole AR (2012) Osteoarthritis as a whole joint disease. HSS J 8:4-6. https://doi.org/10.1007/s11420-011-9248-6

7. Kolasinski SL, Neogi T, Hochberg MC et al (2020) 2019 American College of Rheumatology/Arthritis Foundation guideline for the management of osteoarthritis of the hand, hip, and knee. Arthritis Care Res 72:149-162. https://doi.org/10.1002/ acr. 24131

8. Fuggle NR, Cooper C, Oreffo ROC et al (2020) Alternative and complementary therapies in osteoarthritis and cartilage repair. Aging Clin Exp Res 32:547-560. https://doi.org/10.1007/s4052 0-020-01515-1

9. Xia W, Cooper C, Li M et al (2019) East meets West: current practices and policies in the management of musculoskeletal aging. Aging Clin Exp Res 31:1351-1373. https://doi. org/10.1007/s40520-019-01282-8

10. Bruyère $\mathrm{O}$, Honvo $\mathrm{G}$, Veronese $\mathrm{N}$ et al (2019) An updated algorithm recommendation for the management of knee osteoarthritis from the European Society for Clinical and Economic Aspects of Osteoporosis, Osteoarthritis and Musculoskeletal Diseases (ESCEO). Semin Arthritis Rheum 49:337-350. https ://doi.org/10.1016/j.semarthrit.2019.04.008

11. Chevalier X, Conrozier T (2017) Access to highly purified chondroitin sulfate for appropriate treatment of osteoarthritis: a review. Med Access @ Point Care 1:maapoc.0000022. https ://doi.org/10.5301/maapoc.0000022

12. Bruyère $\mathrm{O}$, Cooper $\mathrm{C}$, Pelletier $\mathrm{JP}$ et al (2016) A consensus statement on the European Society for Clinical and Economic Aspects of Osteoporosis and Osteoarthritis (ESCEO) algorithm for the management of knee osteoarthritis-from evidencebased medicine to the real-life setting. Semin Arthritis Rheum 45:S3-S11. https://doi.org/10.1016/j.semarthrit.2015.11.010

13. Punzi L, Canesi B, Carrabba M et al (2004) Italian consensus on Eular 2003 recommendations for the treatment of knee osteoarthritis. Reumatismo 56:190-201

14. Hochberg MC, Zhan M, Langenberg P (2008) The rate of decline of joint space width inpatientswithosteoarthritis of the knee: a systematic review and meta-analysis of randomized placebo-controlled trials of chondroitin sulfate. Curr Med Res Opin 24:3029-3035. https://doi.org/10.1185/030079908024349 32

15. Hochberg MC (2010) Structure-modifying effects of chondroitin sulfate in knee osteoarthritis: an updated meta-analysis of randomized placebo-controlled trials of 2-year duration. Osteoarthr Cartil 18:S28-S31. https://doi.org/10.1016/j.joca.2010.02.016

16. Honvo $G$, Bruyère $O$, Geerinck $A$ et al (2019) Efficacy of chondroitin sulfate in patients with knee osteoarthritis: a comprehensive meta-analysis exploring inconsistencies in randomized, placebo-controlled trials. Adv Ther. https://doi.org/10.1007/ s12325-019-00921-w

17. Honvo G, Bruyère O, Reginster JY (2019) Update on the role of pharmaceutical-grade chondroitin sulfate in the symptomatic management of knee osteoarthritis. Aging Clin Exp Res 31:11631167. https://doi.org/10.1007/s40520-019-01253-z

18. Brandt Eriksen M, Faber Frandsen T (2018) The impact of patient, intervention, comparison, outcome (PICO) as a search strategy tool on literature search quality: a systematic review. J Med Libr Assoc 106:420-431

19. Conte A, De Bernardi M, Palmieri L et al (1991) Metabolic fate of exogenus chondroitin sulfate in man. Arzneinittel-forsch Drug Res 41:768-772

20. Conte A, Volpi N, Palmieri L et al (1995) Biochemical and pharmacokinetic aspects of oral treatment with chondroitin sulfate. Arzneinittel-forsch Drug Res 45:918-925

21. Volpi N (2003) Oral absorption and bioavailability of ichthyic origin chondroitin sulfate in healthy male volunteers. Osteoarthr Cartil 11:433-441. https://doi.org/10.1016/S1063-4584(03)00051 $-7$

22. Volpi N (2002) Oral bioavailability of chondroitin sulfate (Condrosulf( $\left.{ }^{\circledR}\right)$ and its constituents in healthy male volunteers. Osteoarthr Cartil 10:768-777. https://doi.org/10.1053/joca.2002.0824

23. Bassleer CT, Combal JPA, Bougaret $S$ et al (1998) Effects of chondroitin sulfate and interleukin- $1 \beta$ on human articular chondrocytes cultivated in clusters. Osteoarthr Cartil 6:196-204. https://doi. org/10.1053/joca.1998.0112

24. Ronca F, Palmieri L, Panicucci P et al (1998) Anti-inflammatory activity of chondroitin sulfate. Osteoarthr Cartil 6:14-21. https:// doi.org/10.1016/S1063-4584(98)80006-X

25. Cohen AD, Bonneh DY, Reuveni H et al (2005) Drug exposure and psoriasis vulgaris: case-control and case-crossover studies. Acta Derm Venereol 85:299-303. https://doi.org/10.1080/00015 550510032823

26. Jomphe C, Gabriac M, Hale TM et al (2008) Chondroitin sulfate inhibits the nuclear translocation of nuclear factor- $\kappa \mathrm{B}$ in interleukin-1 $\beta$-stimulated chondrocytes. Basic Clin Pharmacol Toxicol 102:59-65. https://doi.org/10.111 1/j.1742-7843.2007.00158.x

27. Reveliere D, Mentz F, Nterle-Béral H et al (1998) Protective effect of chondroitin $4 \& 6$ sulfate on apoptosis of rabbit articular chondrocytes:preliminary results. Litera Rheumatologica 24:15-20

28. Uebelhart D, Thonar EJ, Zhang J et al (1998) Protective effect of exogenous chondroitin 4,6-sulfate in the acute degradation of articular cartilage in the rabbit. Osteoarthr Cartil 6:6-13 
29. Monfort J, Nacher M, Montell E et al (2005) Chondroitin sulfate and hyaluronic acid (500-730 kDa) inhibit stromelysin- 1 synthesis in human osteoarthritic chondrocytes. Drugs Exp Clin Res XXXI:71-76

30. Monfort J, Pelletier JP, Garcia-Giralt N et al (2008) Biochemical basis of the effect of chondroitin sulphate on osteoarthritis articular tissues. Ann Rheum Dis 67:735-740

31. Nerucci F, Fioravanti A, Cicero MR et al (2000) Effects of chondroitin sulfate and interleukin-1 $\beta$ on human chondrocyte cultures exposed to pressurization: a biochemical and morphological study. J Osteoarthr Res Soc Int 8:279-287. https://doi.org/10.1053/ joca. 1999.0302

32. Du Souich P, García AG, Vergés J et al (2009) Immunomodulatory and anti-inflammatory effects of chondroitin sulphate. J Cell Mol Med 13:1451-1463. https://doi.org/10.111 1/j.1582-4934.2009.00826.x

33. Conrozier T, Vignon E (1992) Effet du sulfate de chondroitine dans le traitement de l'arthrose de la hanche. Etude en double aveugle contre placebo. Litera Rheum 14:69-75

34. Uebelhart D, Thonar EJ, Delmas PD et al (1998) Effects of oral chondroitin sulfate on the progression of knee osteoarthritis: a pilot study. Osteoarthr Cartil 6:39-46

35. Uebelhart D, Malaise M, Marcolongo R et al (2004) Intermittent treatment of knee osteoarthritis with oral chondroitin sulfate: a one-year, randomized, double-blind, multicenter study versus placebo. Osteoarthr Cartil 12:269-276. https://doi.org/10.1016/j. joca.2004.01.004

36. Michel BA, Stucki G, Frey D et al (2005) Chondroitins 4 and 6 sulfate in osteoarthritis of the knee: a randomized, controlled trial. Arthritis Rheum 52:779-786. https://doi.org/10.1002/art.20867

37. Radrigán F, Gutiérrez M, Neira Ó et al (2007) Estudio de la Eficacia del Condroitín 4 y 6 Sulfato en los Síntomas de la Artrosis de Rodilla. Reumatologia 23:33-41

38. Kahan A, Uebelhart D, De Vathaire F et al (2009) Long-term effects of chondroitins 4 and 6 sulfate on knee osteoarthritis: the study on osteoarthritis progression prevention, a two-year, randomized, double-blind, placebo-controlled trial. Arthritis Rheum 60:524-533. https://doi.org/10.1002/art.24255

39. Möller I, Pérez M, Monfort J et al (2010) Effectiveness of chondroitin sulphate in patients with concomitant knee osteoarthritis and psoriasis: a randomized, double-blind, placebo-controlled study. Osteoarthr Cartil 18:S32-S40. https://doi.org/10.1016/j.joca.2010.01.018

40. Wildi LM, Raynauld JP, Martel-Pelletier J et al (2011) Chondroitin sulphate reduces both cartilage volume loss and bone marrow lesions in knee osteoarthritis patients starting as early as 6 months after initiation of therapy: a randomised, double-blind, placebocontrolled pilot study using MRI. Ann Rheum Dis 70:982-989. https://doi.org/10.1136/ard.2010.140848

41. Monfort J, Escudero P, Orellana C et al (2012) Condroitin sulfate decreases chemokine levels and synovitis in knee osteoarthritis patients. Arthritis Rheum 64:1101

42. Reginster JY, Dudler J, Blicharski T et al (2017) Pharmaceuticalgrade chondroitin sulfate is as effective as celecoxib and superior to placebo in symptomatic knee osteoarthritis: the ChONdroitin versus CElecoxib versus Placebo Trial (CONCEPT). Ann Rheum Dis 76:1537-1543. https://doi.org/10.1136/annrheumdis-2016-210860

43. Wang FC, Collignon L, Reginster JY et al (1992) Effet de la prise orale de Chondroitine sulfate dans l'arthrose d'Heberden et de Bouchard. Litera Rheumatologica 14:85-90

44. Verbruggen G, Goemaere S, Veys EM (1998) Chondroitin sulfate: S/DMOAD (structure/disease modifying anti-osteoarthritis drug) in the treatment of finger joint OA. Osteoarthr Cartil 6:37-38. https://doi.org/10.1016/S1063-4584(98)80010-1

45. Rovetta G, Monteforte P, Molfetta G et al (2002) Chondroitin sulfate in erosive osteoarthritis of the hands. Int J Tissue React 24:29-32
46. Rovetta G, Monteforte P, Molfetta G et al (2004) A two-year study of chondroitin sulfate in erosive osteoarthritis of the hands: behaviour of erosions, osteophytes, pain and hand dysfunction. Drugs Exp Clin Res 30:11-16

47. Gabay C, Medinger-Sadowski C, Gascon D et al (2011) Symptomatic effects of chondroitin 4 and chondroitin 6 sulfate on hand osteoarthritis: a randomized, double-blind, placebo-controlled clinical trial at a single center. Arthritis Rheum 63:3383-3391. https://doi.org/10.1002/art.30574

48. Morreale P, Manopulo R, Galati M et al (1996) Comparison of the antiinflammatory efficacy of chondroitin sulfate and diclofenac sodium in patients with knee osteoarthritis. J Rheumatol 23:1385-1391

49. Bourgeois P, Chales G, Dehais J et al (1998) Efficacy and tolerability of chondroitin sulfate $1200 \mathrm{mg} /$ day vs chondroitin sulfate $3 \times 400 \mathrm{mg} /$ day vs placebo. Osteoarthr Cartil 6:25-30

50. Pavelka K, Manopulo R, Bucsi L (1999) Double-blind, dose-effect study of oral chondroitin $4 \& 6$ sulfate $1200 \mathrm{mg}, 800 \mathrm{mg}, 200 \mathrm{mg}$ and placebo in the treatment of knee osteoarthritis. Litera Rheum 24:21-30

51. Clegg DO, Reda JD, Harris CL et al (2006) Glucosamine, chondroitin sulfate, and the two in combination for painful knee osteoarthritis. N Engl J Med 354:795-80854

52. Zegels B, Crozes P, Uebelhart D et al (2013) Equivalence of a single dose (1200 mg) compared to a three-time a day dose (400 $\mathrm{mg}$ ) of chondroitin $4 \& 6$ sulfate in patients with knee osteoarthritis. Results of a randomized double blind placebo controlled study. Osteoarthr Cartil 21:22-27. https://doi.org/10.1016/j. joca.2012.09.017

53. Pelletier JP, Raynauld JP, Beaulieu AD et al (2016) Chondroitin sulfate efficacy versus celecoxib on knee osteoarthritis structural changes using magnetic resonance imaging: a 2-year multicentre exploratory study. Arthritis Res Ther 18:1-12. https://doi. org/10.1186/s13075-016-1149-0

54. Bruyère O, Cooper C, Al-Daghri NM et al (2018) Inappropriate claims from non-equivalent medications in osteoarthritis: a position paper endorsed by the European Society for Clinical and Economic Aspects of Osteoporosis, Osteoarthritis and Musculoskeletal Diseases (ESCEO). Aging Clin Exp Res 30:111-117. https://doi.org/10.1007/s40520-017-0861-1

55. Volpi N, Maccari F (2008) Two analytical approaches to the evaluation of chondroitin sulfate in european food supplements. Sep Sci $1: 3-8$

56. Restaino OF, Finamore R, Stellavato A et al (2019) European chondroitin sulfate and glucosamine food supplements: a systematic quality and quantity assessment compared to pharmaceuticals. Carbohydr Polym 222:114984. https://doi.org/10.1016/j.carbp ol.2019.114984

57. Stellavato A, Restaino OF, Vassallo V et al (2019) Comparative analyses of pharmaceuticals or food supplements containing chondroitin sulfate: are their bioactivities equivalent? Adv Ther 36:3221-3237. https://doi.org/10.1007/s12325-019-01064-8

58. Bruyère $\mathrm{O}$, Scholtissen $\mathrm{S}$, Neuprez $\mathrm{A}$ et al (2009) Impact of chondroitin sulphate on health utility in patients with knee osteoarthritis: towards economic analysis. J Med Econ 12:356-360. https:// doi.org/10.3111/13696990903438617

59. Lagnaoui R, Baumevielle M, Bégaud B et al (2006) Less use of NSAIDs in long-term than in recent chondroitin sulphate users in osteoarthritis: a pharmacy-based observational study in France. Therapie 61:341-346. https://doi.org/10.2515/therapie:2006063

Publisher's Note Springer Nature remains neutral with regard to jurisdictional claims in published maps and institutional affiliations. 